ISSN 1561-8331 (Print)

ISSN 2524-2342 (Online)

УДК 666.76:54.057

https://doi.org/10.29235/1561-8331-2019-55-2-240-246

Поступила в редакцию 18.12 .2018

Received 18.12.2018

\author{
Р. Ю. Попов ${ }^{1}$, Е. О. Богдан ${ }^{1}$, Е. М. Дятлова ${ }^{1}$, М. В. Комар ${ }^{2}$ \\ ${ }^{1}$ Белорусский государственный технологический университет, Минск, Беларусь \\ ${ }^{2}$ Минский керамический завод ОАО «Керамин», Минск, Беларусь \section{СИНТЕЗА ДЛЯ ПОЛУЧЕНИЯ ЗАЩИТНО-УПРОЧНЯЮЩИХ АЛЮМОСИЛИКАТНЫХ ПОКРЫТИЙ} \\ ПРИМЕНЕНИЕ САМОРАСПРОСТРАНЯЮЩЕГОСЯ ВЫСОКОТЕМПЕРАТУРНОГО
}

\begin{abstract}
Аннотация. Показана возможность использования метода самораспространяющегося высокотемпературного синтеза для получения защитно-упрочняющих покрытий по футеровке различных тепловых установок. Разработка составов керамических композиций для получения СВС-покрытий осуществлялась на основе алюминиевой пудры, глинистого сырья, отощающих и флюсующих компонентов, а также минерализующих добавок. Приготовленную суспензию, включающую предварительно подготовленные и тщательно перемешанные сырьевые компоненты, с помощью кисти или пульверизатора наносили на предварительно очищенную и увлажненную поверхность алюмосиликатного огнеупора. Обжиг покрытия осуществляли в соответствии с режимом выведения теплового агрегата на рабочую температуру. Температура инициирования процесса $\mathrm{CBC}$, предварительно установленная с помощью дифференциально-термического анализа, находилась в интервале $570-720^{\circ} \mathrm{C}$ и зависела от химического состав шихты. Установлено, что наличие в структуре покрытий кристаллических фаз кремнезема, корунда, гематита, а также ряда твердых растворов (преимущественно алюмосиликаты кальция и натрия) обеспечивает необходимое сочетание термомеханических и теплофизических характеристик покрытий. На основании проведенных исследований показана целесообразность применения технологии СВС для получения защитно-упрочняющих покрытий по футеровке тепловых агрегатов, что подтверждено промышленными испытаниями в условиях Минского керамического завода ОАО «Керамин».

Ключевые слова: покрытия, самораспространяющийся высокотемпературный синтез, прочность, структура, фазовый состав, термоциклирование

Для цитирования. Применение самораспространяющегося высокотемпературного синтеза для получения защитно-упрочняющих алюмосиликатных покрытий / Р. Ю. Попов [и др.] // Вес. Нац. акад. навук Беларусі. Сер. хім. навук. - 2019. - Т. 55, № 2. - С. 240-246. https://doi.org/10.29235/1561-8331-2019-55-2-240-246
\end{abstract}

\author{
R. Yu. Popov ${ }^{1}$, E. O. Bohdan ${ }^{1}$, E. M. Dyatlova ${ }^{1}$, M. V. Komar ${ }^{2}$ \\ ${ }^{1}$ Belarusian State Technological University, Minsk, Belarus \\ ${ }^{2}$ Minsk Ceramic Factory OJSC «Keramin», Minsk, Belarus
}

\title{
THE APPLICATION OF SELF-PROPAGATING HIGH-TEMPERATURE SYNTHESIS TO OBTAIN A PROTECTIVE-STRENGTHENING ALUMINA-SILICA COATINGS
}

\footnotetext{
Abstract. This article shows the possibility of using the method of self-propagating high-temperature synthesis to obtain protective and hardening coatings for the lining of various thermal installations. The development of compositions of ceramic masses for the production of SHS coatings was carried out on the basis of aluminum powder, clay raw materials, exhausting and fluxing components as well as mineralizing additives. The prepared suspension including pre-prepared and thoroughly mixed raw materials was applied with a brush or a spray gun onto the previously cleaned and moistened surface of an aluminosilicate refractory. The firing of the coating was carried out in accordance with the mode of removing the thermal unit at the operating temperature. The temperature of the initiation of the SHS process, previously established using differential thermal analysis, was in the range of $570-720^{\circ} \mathrm{C}$ and depended on the chemical composition of the charge. It has been established that the presence of crystalline phases of silica, corundum, hematite and a number of solid solutions (mainly calcium and sodium aluminosilicates) in the coating structure provides the necessary combination of the thermomechanical and thermophysical characteristics of the coatings. On the basis of the conducted research, the expediency of applying the technology of self-propagating high-temperature synthesis for the production of protective and hardening coatings on the lining of thermal units is demonstrated, which is confirmed by industrial tests in the conditions of the Minsk Ceramic Factory OJSC «Keramin».

Keywords: coatings, self-propagating high-temperature synthesis, strength, structure, phase composition, thermal cycling

For citation: Popov R. Yu., Bohdan E. O., Dyatlova E. M., Komar M. V. The application of self-propagating hightemperature synthesis to obtain a protective-strengthening alumina-silica coatings. Vestsi Natsyyanal'nai akademii navuk Belarusi. Seryya khimichnykh navuk = Proceedings of the National Academy of Sciences of Belarus. Chemical series, 2019, vol. 55, no. 2, pp. 240-246 (in Russian). https://doi.org/10.29235/1561-8331-2019-55-2-240-246
} 
Введение. Самораспространяющийся высокотемпературный синтез (СВС) - химический процесс горения, протекающий в автоволновом режиме в смесях порошков различных сырьевых компонентов, включающих металлы, активно окисляющиеся при воздействии температур или электрического разряда (локальное инициирование процесса зажигания шихты от внешнего источника) и приводящих к образованию полезных конденсированных продуктов, материалов и изделий. Для большинства существующих составов эта температура составляет $570-900{ }^{\circ} \mathrm{C}$. При данном процессе тепловыделение локализовано в узком слое и передается от слоя к слою путем теплопередачи, а получаемые при синтезе продукты характеризуются достаточной чистотой, что объясняется развитием высоких температур. Достоинство технологии заложено в использовании теплоты, выделяющейся при протекании химической реакции, вместо нагрева вещества, что подразумевает снижение энергоемкости процесса при одновременном развитии высоких температур синтеза вплоть до $2000{ }^{\circ} \mathrm{C}[1,2]$.

Достоинствами применения и развития данной технологии является относительная простота ее реализации, но в то же время существуют и недостатки: сложность управления процессом синтеза и быстрота его протекания, что не всегда позволяет достигать необходимых результатов (получение изделий заданных размеров, достижение необходимых прочностных характеристик, заданной пористости) [2, 3].

Использование метода СВС целесообразно при получении огнезащитных покрытий, а также в случае выполнения ремонтных работ в различных тепловых установках или агрегатах, особенно при восстановлении футеровки вращающихся печей, печных вагонеток, а также с целью продления срока службы футеровки. Весьма перспективным является применение CBC-покрытий для защиты футеровки печей для плавки черных и цветных металлов, соляных ванн для обработки инструментальных сталей, а также футеровки тепловых агрегатов и печных вагонеток, применяющихся при производстве керамических материалов [4].

Нанесенные на поверхность огнеупоров покрытия расширяют область температурного применения огнеупорной основы, приводят к значительному снижению физико-химической и механической эрозий поверхности, повышают температурный ресурс огнеупоров в условиях статических и динамических (в том числе циклических) воздействий агрессивных сред, высокотемпературных газовых и пылевых потоков.

Как известно, наиболее распространенные огнеупорные материалы, применяющиеся в конструкциях различных тепловых агрегатов, алюмосиликатные. Такому широкому распространению указанных огнеупоров способствует доступность сырьевых материалов, их относительно низкая стоимость, простота изготовления изделий, а также необходимые эксплуатационные свойства. Так, механическая прочность при сжатии шамотных огнеупоров составляет от 12 до 30 МПа; огнеупорность - от 1600 до $1750{ }^{\circ} \mathrm{C}$, температура начала деформации под нагрузкой - выше $1300{ }^{\circ} \mathrm{C}$, термостойкость (нагрев $1300{ }^{\circ} \mathrm{C}$ - вода) - 10-25 теплосмен. Несмотря на значительные достоинства данных огнеупоров, они характеризуются и некоторыми недостатками: недостаточная термостойкость, а также малая прочность. Совместное влияние механического и термического воздействий приводит к быстрому износу футеровки и ее выкрашиванию, что в итоге снижает эффективность применения тепловых агрегатов в результате простоя теплотехнического оборудования, необходимого для его ремонта и обслуживания.

CBC-покрытия образуются на поверхности шамотных огнеупоров в процессе инициирования реакции СВС в обычном режиме эксплуатации тепловых агрегатов при $700-800{ }^{\circ} \mathrm{C}$. Использование покрытий способствует повышению теплофизических (прочностных и термических) характеристик, а также химической стойкости футеровки, что увеличивает срок ее службы.

Цель работы - разработка составов керамических композиций для получения CBC-покрытий для защиты конструкционных элементов теплотехнических установок.

Материалы и методы. В качестве сырьевых компонентов применялись следующие материалы: алюминиевая пудра марки ПАП-1 или ПАП-2 (ГОСТ 5494 - 95), глинистое сырье, натрий кремнефтористый (ГОСТ 87-77), оксид железа (III), электрокорунд (ГОСТ 28818-90), гранитоидные отсевы (ГОСТ 8267-93), нефелин-сиенит, стеклобой (ГОСТ Р 52233-2004), отходы производства глазурей (ОПГ), образующиеся на ОАО «Керамин» (таблица). 
242 Proceedings of the National Academy of Sciences of Belarus, Chemical series, 2018, vol. 54, no. 2, pp. $240-246$

Т а б л и ц а 1 . Химический состав сырьевых компонентов

$\mathrm{T}$ a b 1 e 1 . Chemical composition of raw materials

\begin{tabular}{|c|c|c|c|c|c|c|c|c|c|c|c|c|}
\hline \multirow{2}{*}{ Наименование сырья } & \multicolumn{12}{|c|}{ Наименование оксидов и их содержание, \% } \\
\hline & $\mathrm{SiO}_{2}$ & $\mathrm{Al}_{2} \mathrm{O}_{3}$ & $\mathrm{Fe}_{2} \mathrm{O}_{3}$ & $\mathrm{TiO}_{2}$ & $\mathrm{CaO}$ & $\mathrm{MgO}$ & $\mathrm{K}_{2} \mathrm{O}$ & $\mathrm{Na}_{2} \mathrm{O}$ & $\mathrm{ZrO}_{2}$ & $\mathrm{BaO}$ & $\mathrm{B}_{2} \mathrm{O}_{3}$ & ппп \\
\hline Алюминиевая пудра & - & 99,98 & - & - & - & - & - & - & - & - & - & 0,02 \\
\hline Полиминеральная глина & 52,12 & 17,56 & 7,91 & 0,88 & 5,10 & 2,86 & 4,52 & 0,70 & - & - & - & 8,35 \\
\hline Каолин & 70,38 & 19,00 & 0,46 & 0,26 & 0,09 & - & 6,02 & 0,10 & - & - & - & 3,69 \\
\hline Электрокорунд & - & 93,14 & 0,76 & 1,83 & 1,04 & - & - & - & - & - & - & 3,23 \\
\hline Кварцевый песок & 99,8 & - & 0,08 & - & - & & - & - & - & - & - & 0,12 \\
\hline Кремнефтористый натрий & 30,3 & - & - & - & - & - & - & 31,30 & - & - & - & 38,40 \\
\hline Оксид железа (III) & - & - & 98,64 & - & - & - & - & - & & & - & 1,36 \\
\hline Алюмосиликатный шамот & 32,51 & 64,14 & 0,67 & 0,4 & 0,14 & 0,06 & 2,07 & 0,01 & - & - & - & - \\
\hline Гранитоидные отсевы & 53,94 & 17,44 & 8,80 & 0,90 & 6,43 & 3,25 & 3,59 & 3,91 & - & - & - & 1,74 \\
\hline ОПГ & 29,58 & 10,54 & - & - & 14,63 & 0,23 & 3,14 & 2,34 & 2,40 & 4,54 & 0,94 & 31,66 \\
\hline
\end{tabular}

${ }^{1}$ Здесь и далее по тексту содержание приведено в массовых процентах.



Рис. 1. Дифрактограмма отходов производства глазури

Fig. 1. Diffraction pattern of the glaze waste $(\mathrm{GW})$

Использование отходов производства глазурей в качестве компонента сырьевой композиции будет способствовать не только интенсификации спекания покрытия, но и насыщению материала оксидами $\mathrm{SiO}_{2}, \mathrm{ZrO}_{2}$, что приведет к формированию кристаллических фаз, обеспечивающих высокую износостойкость и механическую прочность покрытий. Фазовый состав отходов производства глазурей, образующихся на ОАО «Керамин», представлен преимущественно цирконом, $\alpha$-кварцем и волластонитом (рис. 1). Значительная площадь имеющегося на рентгенограмме гало свидетельствует о наличии в составе аморфной стекловидной фазы.

Анализ интегральных и дифференциальных кривых распределения частиц по размерам (рис. 2) свидетельствует, что исследуемые отходы производства глазурей являются полидисперсными материалами с различным содержанием частиц и их агломератов размером от 0,2 до 7 мкм. Причем содержание фракции 1-5 мкм составляет около 70 \%.

Результаты и их обсуждение. Важной составляющей сырьевых композиций является кремнефтористый натрий $\left(\mathrm{Na}_{2} \mathrm{SiF}_{6}\right)$, который обеспечивает интенсивное образование расплава совместно с другими компонентами (например, оксидом железа). Предварительно подготовленные сырьевые компоненты дозировали согласно рецептуре и тщательно перемешивали в сухом виде в шаровой мельнице в течение 15-20 мин. Затем с целью повышения однородности полученный порошок просеивали через сито с размерами ячейки 0,1 мм.

В подготовленную и усредненную массу добавляли связующее, в качестве которого выступало жидкое стекло, затем добавляли воду. Перемешивание осуществляли с помощью промыш- 


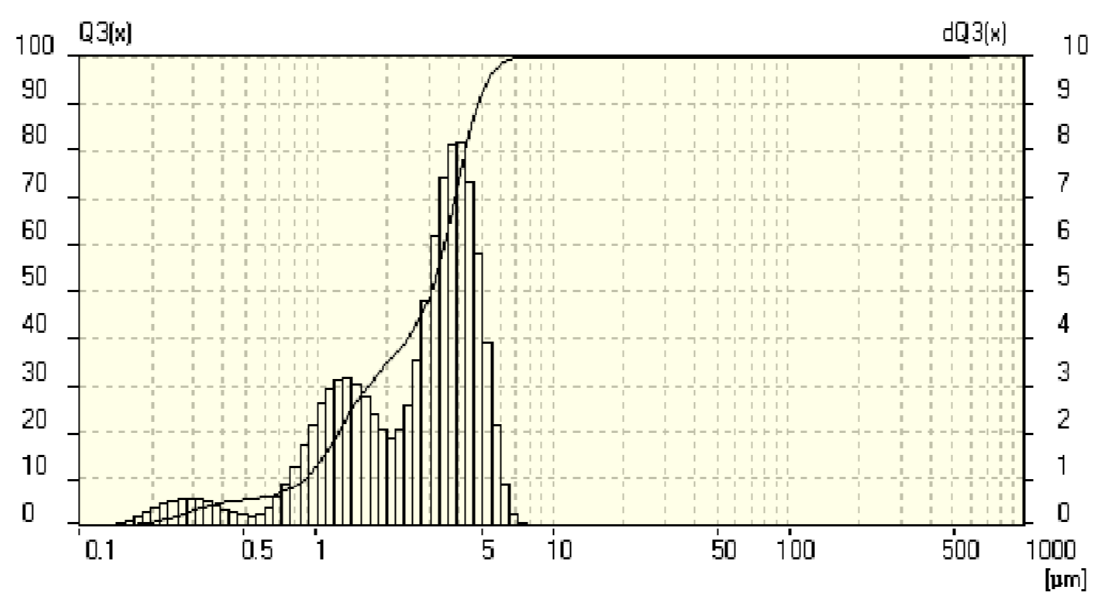

Рис. 2. Кривые интегрального и дифференциального распределения частиц ОПГ по размерам

Fig. 2. Curves of the integral and differential GW particle size distribution

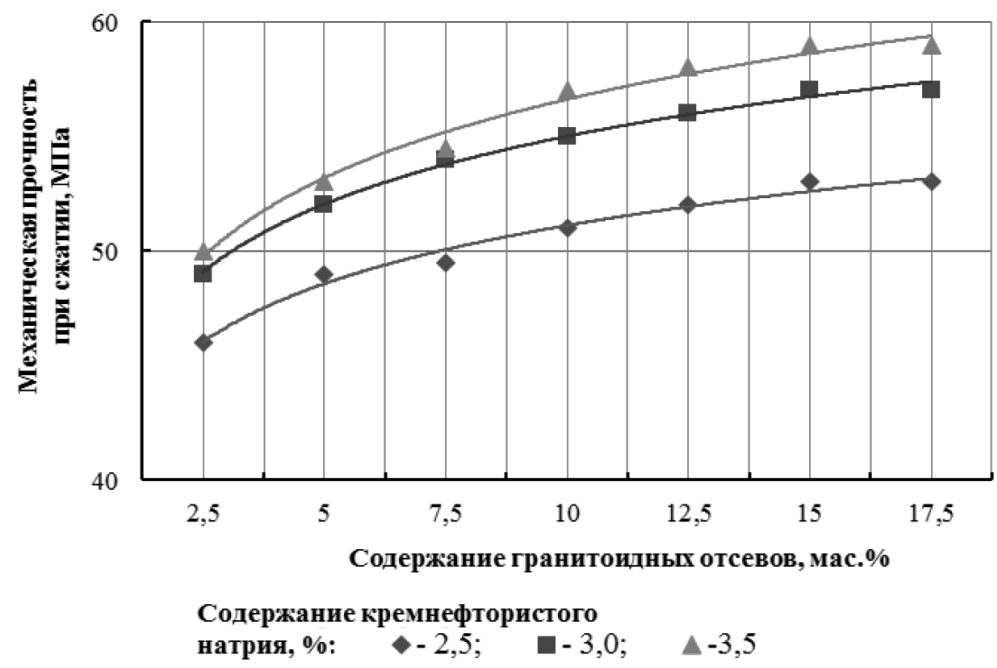

Рис. 3. Зависимость механической прочности при сжатии образцов покрытий от содержания гранитоидных отсевов и кремнефтористого натрия $\left(T_{\text {обж. }}=1150{ }^{\circ} \mathrm{C}\right)$

Fig. 3. The dependence of mechanical compression resistance of the coating samples on the content of granitic screenings and sodium silicofluoride $\left(T_{\text {fir. }}=1150{ }^{\circ} \mathrm{C}\right)$

ленного миксера до получения однородной суспензии с влажностью 35-40 \%. Приготовленную суспензию с помощью кисти или пульверизатора наносили на предварительно очищенную и увлажненную поверхность алюмосиликатного огнеупора, толщина нанесенного покрытия составляла 1-2 мм. После сушки в естественных условиях проводили обжиг покрытия в соответствии с режимом выведения теплового агрегата на рабочую температуру. Следует отметить, что температура инициирования процесса СВС, предварительно установленная с помощью дифференциально-термического анализа, находилась в интервале $570-720{ }^{\circ} \mathrm{C}$ и зависела от химического соства шихты.

Предполагается, что разрабатываемые покрытия будут наноситься на футеровку тепловых установок, работающих при температурах $1100-1150{ }^{\circ} \mathrm{C}$. В связи с этим представляют интерес свойства покрытий, полученных методом СВС, при повторном обжиге при температуре $1150{ }^{\circ} \mathrm{C}$. Зависимость механической прочности при сжатии $\mathrm{CBC}$-покрытий, обожженных при $1150{ }^{\circ} \mathrm{C}$, от содержания гранитоидных отсевов и кремнефтористого натрия представлена на рис. 3.

Установлено, что повышение содержания в сырьевых композициях гранитоидных отсевов (от 2,5 до 17,5 \%) и кремнефтористого натрия (от 2,5 до 3,5 \%) обеспечивает увеличение проч- 




Рис. 4. Влияние отхода производства глазурей на водопоглощение покрытий

Fig. 4. The influence of glaze production waste on the water absorption of coatings

ности полученных покрытий на 5-18 \%. Это связано, по нашему мнению, с интенсивным формированием стекловидной фазы за счет совместного влияния указанных выше компонентов, что повышает степень спекания покрытия, а также с формированием мелкокристаллических образований сложного состава при завершении процесса самораспространяющегося синтеза.

Следует отметить, что введение в состав экспериментальных композиций отхода производства глазурей ОАО «Керамин» интенсифицирует процессы спекания. Как видно из рис. 4, повышение содержания ОПГ от 2,5 до 10 \% способствует уменьшению водопоглощения на 10-20\%. При этом наблюдается увеличение прочностных характеристик покрытий на 8-15\%.

Рентгенофазовый анализ, проведенный с помощью рентгеновского дифрактометра D8 Advance фирмы Bruker (Германия), позволил установить, что основными кристаллическими фазами большинства синтезированных покрытий являются $\alpha$-кварц, корунд, гематит, а также ряд твердых растворов (преимущественно алюмосиликаты кальция и натрия) криптокристаллической структуры (рис. 5). Наличие в структуре материала указанных кристаллических фаз обеспечивает необходимое сочетание термомеханических и теплофизических характеристик покрытий.

Исследование морфологии поверхности образцов проводили на аттестованном сканирующем электронном микроскопе «Mira» фирмы «Tescan» (Чехия) в режиме отраженных электронов при ускоряющем напряжении 20 кэВ. Результаты представлены на рис. 6. Установлено, что

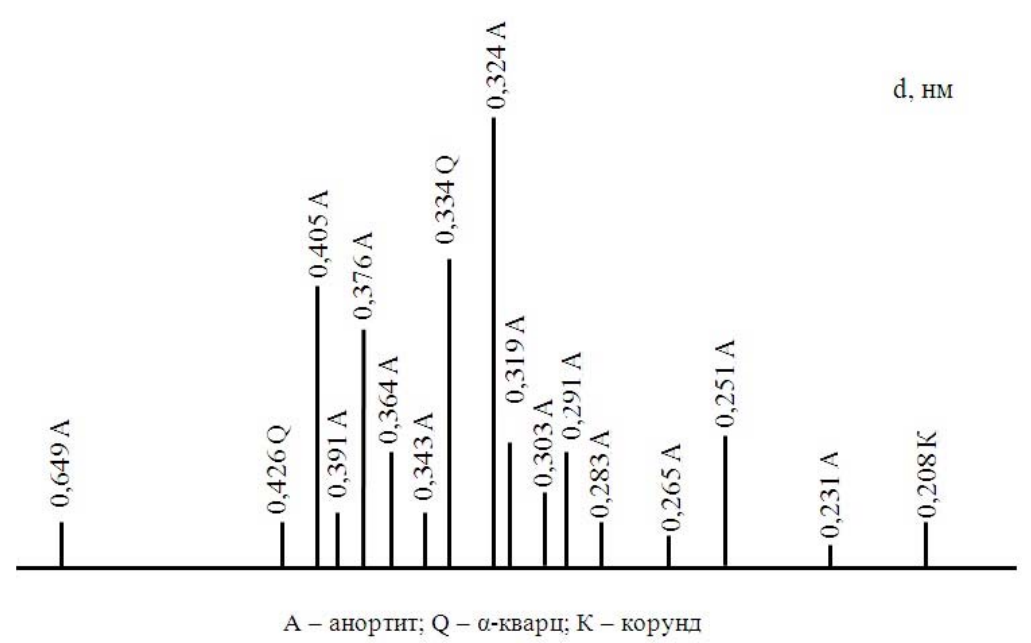

Рис. 5. Штрих-рентгенограмма СВС-покрытия, обожженного при температуре $1150{ }^{\circ} \mathrm{C}$

Fig. 5. X-ray diffractogram of the SHS-coating annealed at $1150^{\circ} \mathrm{C}$ 

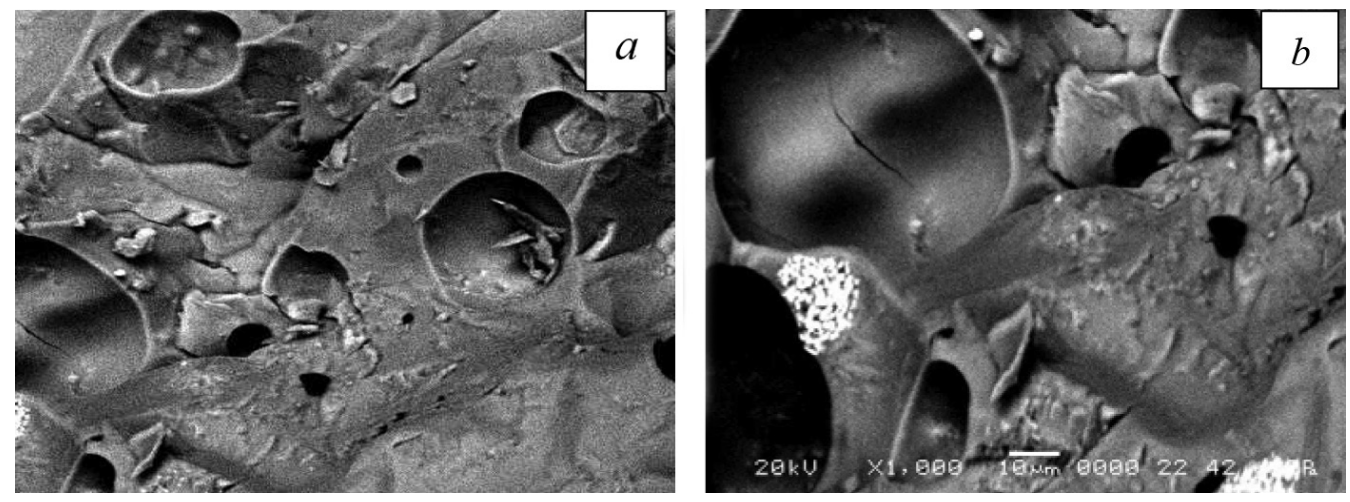

Рис. 6. ЭМ-снимки с поверхности СВС-покрытий, термообработанных при $1150^{\circ} \mathrm{C}(a, \times 300)$ и $(b, \times 1000)$

Fig. 6. SEM images of the surfaces of SHS coatings annealed at $1150^{\circ} \mathrm{C}(a, \times 300)$ and $(b, \times 1000)$

поверхность СВС-покрытий, термообработанных при $1150{ }^{\circ} \mathrm{C}$, характеризуется достаточно однородной структурой. Все составляющие фазы (кристаллические и стекловидная) относительно равномерно распределены в структуре материала, четко фиксируются зерна кварца и гематита.

Как видно из рис. 7, СВС-покрытие характеризуется более плотной структурой по сравнению со структурой алюмосиликатного огнеупора. На поверхности огнеупора имеются области, характеризующиеся существенными неоднородностями: присутствуют трещины, а также крупные зерна шамота. В структуре защитного покрытия присутствуют мелкие зерна наполнителя, однако материал характеризуется мелкозернистой однородной, массивной структурой, в которой отсутствуют дефекты. Граница раздела фаз «СВС-покрытие-огнеупор» обозначена стрелками.

Покрытия оптимального состава, полученные по технологии СВС и дополнительно обожженные при температуре $1150{ }^{\circ} \mathrm{C}$, характеризовались следующим набором физико-технических свойств: водопоглощение - 12,0 \%; открытая пористость $-23,0 \%$; кажущаяся плотность $-1890 \mathrm{\kappa r} / \mathrm{M}^{3}$; твердость по шкале Мооса - 8; теплопроводность $\left(T=200{ }^{\circ} \mathrm{C}\right)-0,400-0,548 \mathrm{BT} /(\mathrm{м} \cdot \mathrm{K})$. Температурный коэффициент линейного расширения покрытий составлял $(2,3-4) \cdot 10^{-6} \mathrm{~K}^{-1}$, что согласуется с ТКЛР шамотных алюмосиликатных огнеупоров.

Защитно-упрочняющие покрытия оптимального состава были испытаны в условиях Минского керамического завода ОАО «Керамин». Суспензию готовили по вышеописанной технологии и наносили на очищенную и слабоувлажненную поверхность алюмосиликатного блока печных вагонеток размером 400×400 мм туннельной печи фирмы «Sacmi», использующейся при

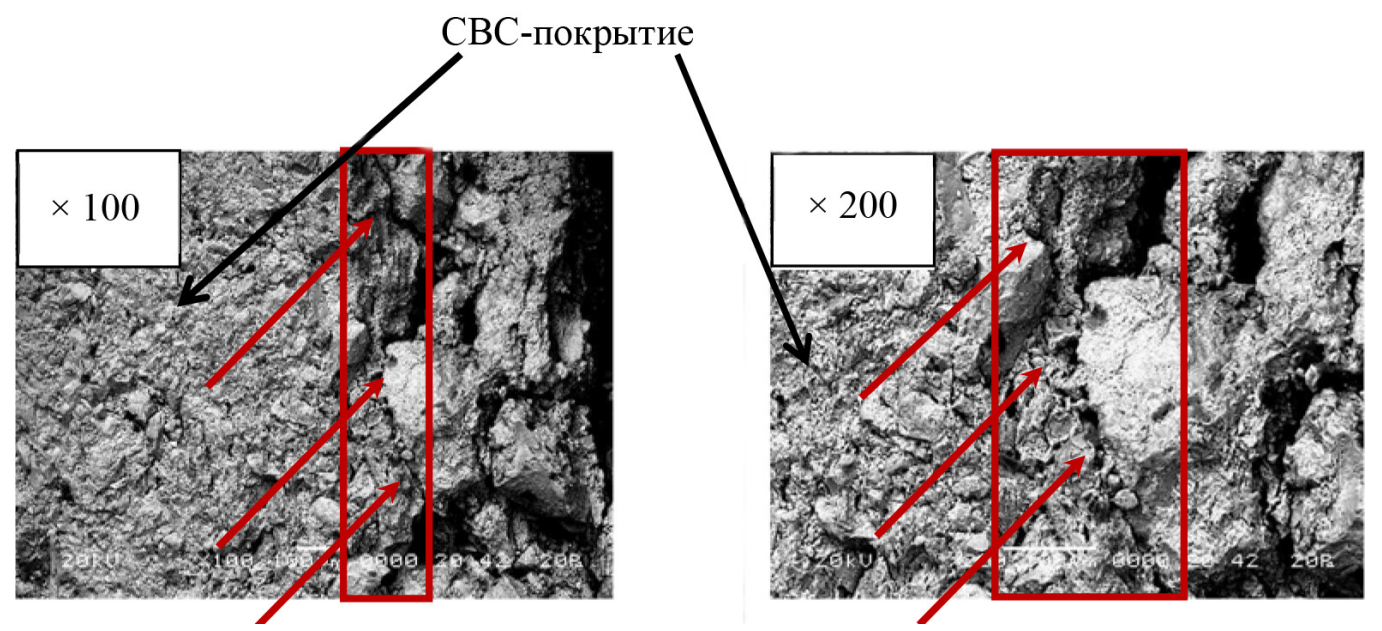

Рис. 7. ЭМ-снимки области адгезионного контакта (выделены красным цветом) защитного покрытия и огнеупора

Fig. 7. SEM images of the area of adhesive contact (highlighted in red) of the protective coating and refractory material 
производстве керамического кирпича. Толщина наносимого слоя покрытия составляла 1,2-1,5 мм. Покрытие, нанесенное на алюмосиликатный блок печной вагонетки, выдержало более 15 теплосмен без видимых внешних дефектов и потери своих эксплуатационных характеристик и продолжает дальнейшую работу в условиях термоциклирования в туннельной печи в интервале температур $40-1050{ }^{\circ} \mathrm{C}$.

В условиях ОАО «Керамин» проведены испытания разработанных покрытий на износостойкость (ГОСТ 27180) при нагружении шлифовального диска под давлением 0,06 МПа с помощью абразивного материала, в качестве которого выступал кварцевый песок. Полученные результаты свидетельствуют, что указанная характеристика находится в пределах $0,12-0,15$ г/см².

Таким образом, на основании проведенных исследований показана целесообразность применения технологии самораспространяющегося высокотемпературного синтеза для получения защитно-упрочняющих покрытий по футеровке тепловых агрегатов. Установлено положительное влияние кремнефтористого натрия и отходов производства глазурей на физико-технические характеристики покрытий. Показано, что использование разработанных составов позволяет существенно повысить прочностные характеристики футеровочного материала при сохранении достаточной термостойкости и достижении высокой твердости.

\section{Список использованной литературы}

1. Мержанов, А. Г. Концепция развития самораспространяющегося высокотемпературного синтеза как области научно-технического прогресса / А. Г. Мержанов, А. М. Столин. - М.: ИСМАН, 2003. - 367 с.

2. Амосов, А. П. Порошковая технология самораспространяющегося высокотемпературного синтеза материалов: учеб. пособие / А. П. Амосов, И. П. Боровинская, А. Г. Мержанов; под науч. ред. В. Н. Анциферова. - М.: Машиностроение, 2007. -254 c.

3. Волочко, А. Т. Огнеупорные и тугоплавкие керамические материалы / А. Т. Волочко, К. Б. Подболотов, Е. М. Дятлова. - Минск: Беларус. навука, - 2013. - 385 с.

4. Шихта для изготовления защитно-упрочняющего композиционного керамического покрытия: пат. 12972 С 1 РБ, МПК (2009) С 04В 41/87 C 04В 35/65 / А. Т. Волочко, К. Б Подболотов, Е. М. Дятлова. - Опубл. 30.04.2009.

\section{References}

1. Merzhanov A. G., Stolin A. M. The concept of development of self-propagating high-temperature synthesis as a field of scientific and technical progress. Moscow, ISMAN Publ., 2003. 367 p. (in Russian).

2. Amosov A. P., Borovinskaya I. P., Merzhanov A. G. Powder technology of self-propagating high-temperature synthesis of materials. Moscow, Mashinostroenie Publ., 2007. 254 p. (in Russian).

3. Volochko A. T., Podbolotov K. B., Dyatlova E. M. Refractory and infusible ceramic materials. Minsk, Belaruskaya navuka Publ., 2013. 385 p. (in Russian).

4. Volochko A. T., Podbolotov K. B., Dyatlova E. M. The mixture for the manufacture of protective-reinforcing composite ceramic coating. Patent Republic of Belarus no. 12972. Publ. date. 30.04 .2009 (in Russian).

\section{Информация об авторах}

Попов Ростислав Юрьевич - канд. техн. наук, доцент, Белорусский государственный технологический университет (ул. Свердлова, 13а, 220006, Минск, Республика Беларусь). E-mail: rospopov@mail.ru

Богдан Екатерина Олеговна - канд. техн. наук, доцент, Белорусский государственный технологический университет (ул. Свердлова, 13a, 220006, Минск, Республика Беларусь). E-mail: Bohdan_Ekaterina@mail.ru

Дятлова Евгения Михайловна - канд. техн. наук, доцент, доцент, Белорусский государственный технологический университет (ул. Свердлова, 13a, 220006, Минск, Республика Беларусь). E-mail: dyatlova@belstu.by

Комар Максим Владимирович - начальник лаб. по контролю производства Минского керамического завода ОАО «Керамин» (ул. Осиповичская, 16, 220024, Минск, Республика Беларусь). E-mail: komarmv@keramin.com

\section{Information about the authors}

Rostislav Yu. Popov - Ph. D. (Engineering), Assosiate Professor, Belarusian State Technological University (13a, Sverdlov Str., 220006, Minsk, Republic of Belarus). E-mail: popov@belstu.by

Ekaterina O. Bohdan - Ph. D. (Engineering), Assosiate Professor, Belarusian State Technological University (13a, Sverdlov Str., 220006, Minsk, Republic of Belarus). E-mail: Bohdan_Ekaterina@mail.ru

Evgeniya M. Dyatlova - Ph. D. (Engineering), Assosiate Professor, Belarusian State Technological University (13a, Sverdlov Str., 220006, Minsk, Republic of Belarus). E-mail: dyatlova@belstu.by

Maxim V. Komar - Head of the Laboratory for the Control of Production of the Minsk Ceramic Factory OJSC «Keramin» (16, Osipovichskaya Str., 220024, Minsk, Republic of Belarus).E-mail: komarmv@keramin.com 